\title{
Modeling Flow and Nitrate Transport in an Over- Exploited Aquifer of Rural Basin Using an Integrated System: The Case of Lake Karla Watershed ${ }^{+}$
}

\author{
Pantelis Sidiropoulos *, Georgios Tziatzios, Lampros Vasiliades, George Papaioannou, \\ Nikitas Mylopoulos and Athanasios Loukas \\ Laboratory of Hydrology and Aquatic Systems Analysis, Department of Civil Engineering, School of \\ Engineering, University of Thessaly, Volos 8334, Greece; getziatz@uth.gr (G.T.); lvassil@uth.gr (L.V.); \\ gpapaioa@uth.gr (G.P.); nikitas@civ.uth.gr (N.M.); aloukas@civ.uth.gr (A.L.) \\ * Correspondence: psidirop@uth.gr ; Tel.: +30-24210-74153 \\ + Presented at the 3rd EWaS International Conference on "Insights on the Water-Energy-Food Nexus", \\ Lefkada Island, Greece, 27-30 June 2018.
}

Published: 1 August 2018

\begin{abstract}
The paper proposes an integrated modeling system consisting of a surface hydrology model, a water reservoir model, a Lake-Aquifer Interaction model, aground water model, and a transport and dispersion model to study ground water quality through two different operational management scenarios. The first scenario is examining the existing condition of groundwater quality without the reservoir operation while the second scenario is assessing the impact of the reconstruction of Lake Karla in the groundwater quality. The study highlights the importance of using an integrated hydrological modeling approach to investigate the groundwater quality in a region which is characterized by extensive agricultural activity.
\end{abstract}

Keywords: nitrate transport modeling; lake karla aquifer; integrated modeling system; water resources management

\section{Introduction}

Nowadays, hydrologic impacts of climate, land-use, and other natural anthropogenic change is a scientific endeavor that is necessary on the water resources management. Addressing this need Integrated Surface and Ground Water Modeling is used in water resources research and management of watershed-scale hydrologic cycle. The integrated approach is required because traditional hydrology focus only on a single component cannot properly predict the effects of changing conditions and feedbacks. Moreover, integrated approach provides spatial and temporal distribution for a large variety of hydrological and hydraulic parameters [1,2]. Lakes and artificial reservoirs are important coefficients of hydrologic and land biogeochemical water cycle. They affect flow regimes by changing the magnitude and timing of stream flow, usually by attenuating and delaying flows [3]. From the groundwater point of view, a reservoir which is in a hydraulic contact with an aquifer leads to increase the renewable groundwater resources. Moreover, it contributes to the raising of groundwater level due to the possibility that part of the restored water in the reservoir can be used to cover irrigation requirements $[3,4]$.

The objective of this work is to study and analyze the importance of the reservoir of Lake Karla basin on groundwater quality regarding to the nitrate parameter. Nitrates are characterized as water soluble contaminants. Nitrate easily dissolves in water but it is very difficult to remove [5,6]. Among various fertilizers, the use of nitrogenous fertilizers in the last 50 years accounted for $60-80 \%$ of the total use [7]. According to Peña-Haro et al. (2010) nitrate can be lost from the system in a variety of 
ways [5]. From the groundwater quality point of view, nitrate leaching into groundwater is the only concern. Leaching is defined as the downward movement of water and nitrate through the soil on the aquifer. The potential for nitrate leaching depends on soil physical characteristics, soil type and the amount of water in precipitation and irrigation $[5,6]$.

\section{Study Area}

Lake Karla watershed is a rural basin and is located at the southern eastern edge of the Larissa plain and is a closed basin $35 \mathrm{~km}$ length and $9-15 \mathrm{~km}$ width (Figure 1). There are two altitude zones (sub-basins); the mountainous zone (altitude $\geq 200 \mathrm{~m}$ ) and the lowland zone (with altitude $<200 \mathrm{~m}$ ). The aquifer of the study area is entirely located in the low altitude zone. The major crops cultivated in the basin are cotton, wheat, alfalfa, maize, and trees. The intense and extensive cultivation, especially of water demanding crops such as cotton and maize, has led to a remarkable water demand increase which is usually determined by the over-exploitation of groundwater resources [8,9]. In addition, overpopulation and the increasing food production demand lead to excessive nitrogen fertilization, increased crop production as well as quality improvement $[5,6]$. The geological structure consists mainly of recent grains of varying size originally from Lake Karla deposits. The plain consists of aquiferous, essentially sand intercalations separated by layers of clay to silt-clay and Neogene deposits consisting of marls and conglomerates and is bound by schists and karstic lime stones or marbles. Impermeable geological structures cover $30.6 \%$ of the total area, karstic aquifers cover $14.5 \%$ and permeable structures, which dominate on the plain, cover $42.7 \%$. The basement rocks consist of impermeable marbles and schists. The watershed boundaries in the east are the Mavrovouni Mountain which consists of impermeable bedrocks as schist whereas in the southwest the Halkodonio Mountain is located [9].

Water supply wells operate at the studied area of aquifer in order to cover the demands in potable water of the city of Volos and of the surrounding villages. The basin has been characterized as one of the seven vulnerable zones of Greece according to the requirements of the Directive 91/676/EEC with respect to nitrogen pollution from agricultural run-offs.

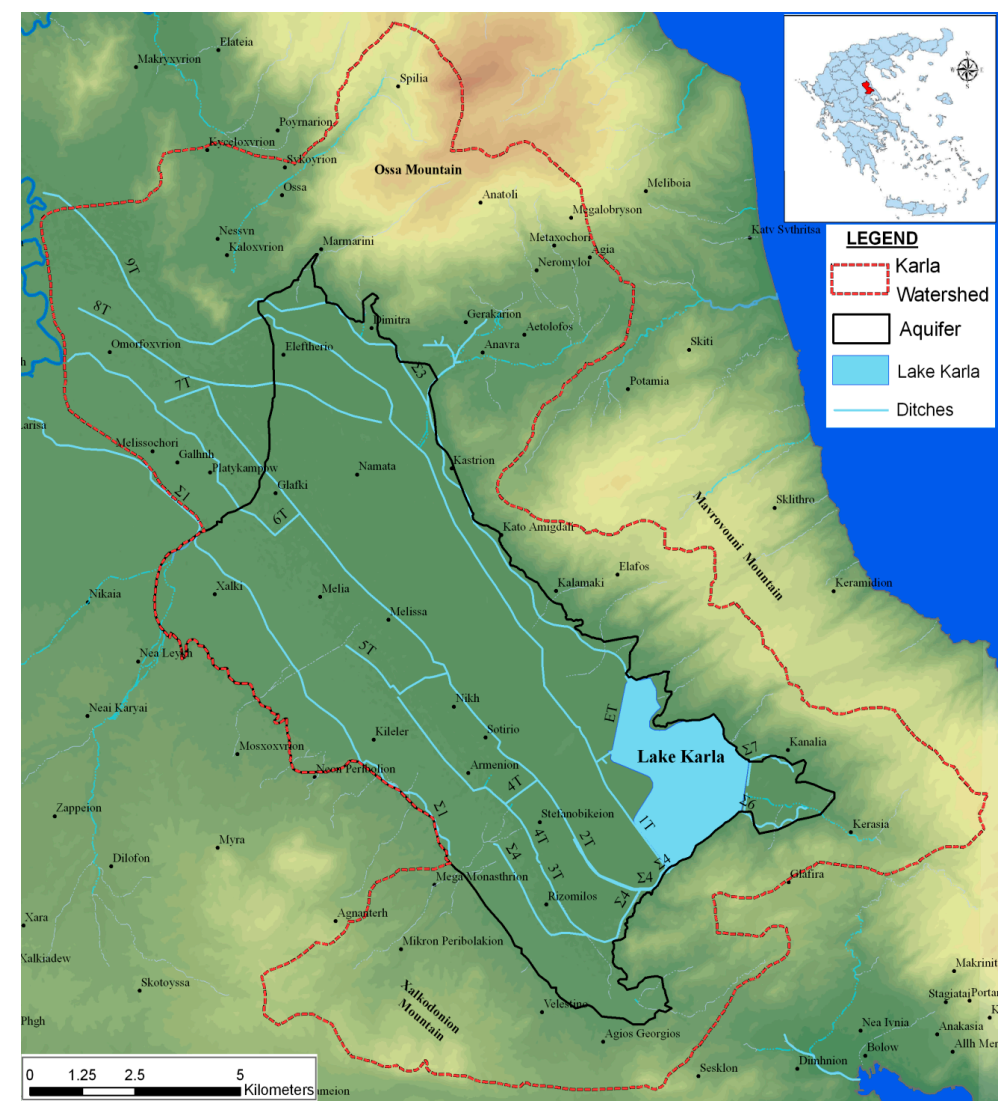

Figure 1. Map of the study area indicating the reservoir. 


\section{Materials and Methods}

In this study, an integrated modeling system has been applied on a monthly basis for the period 1995-2007. The modeling system, shown in Figure 2, consists of the UTHBAL [7] for the assessment of the surface hydrology and groundwater recharge, the UTHRL [8] for reservoir operation simulation, the LAK3 [10] for reservoir/lake-aquifer interaction simulation, the USGS MODFLOW [11] for groundwater flow simulation and finally MT3DMS [12] for nitrates transport and dispersion simulation. The modeling system of UTHBAL, UTHRL, LAK3 and MODFLOW has been calibrated and successfully applied to Lake Karla watershed by $[9,13]$. MT3DMS is the new model added in the system, proposed by this study. MT3DMS utilizes the groundwater recharge from UTHBAL, the nitrate leaching by the use of agrochemicals on cultivations, and the groundwater flow velocity from MODFLOW for the assessment of groundwater quality regarding the nitrate parameter.

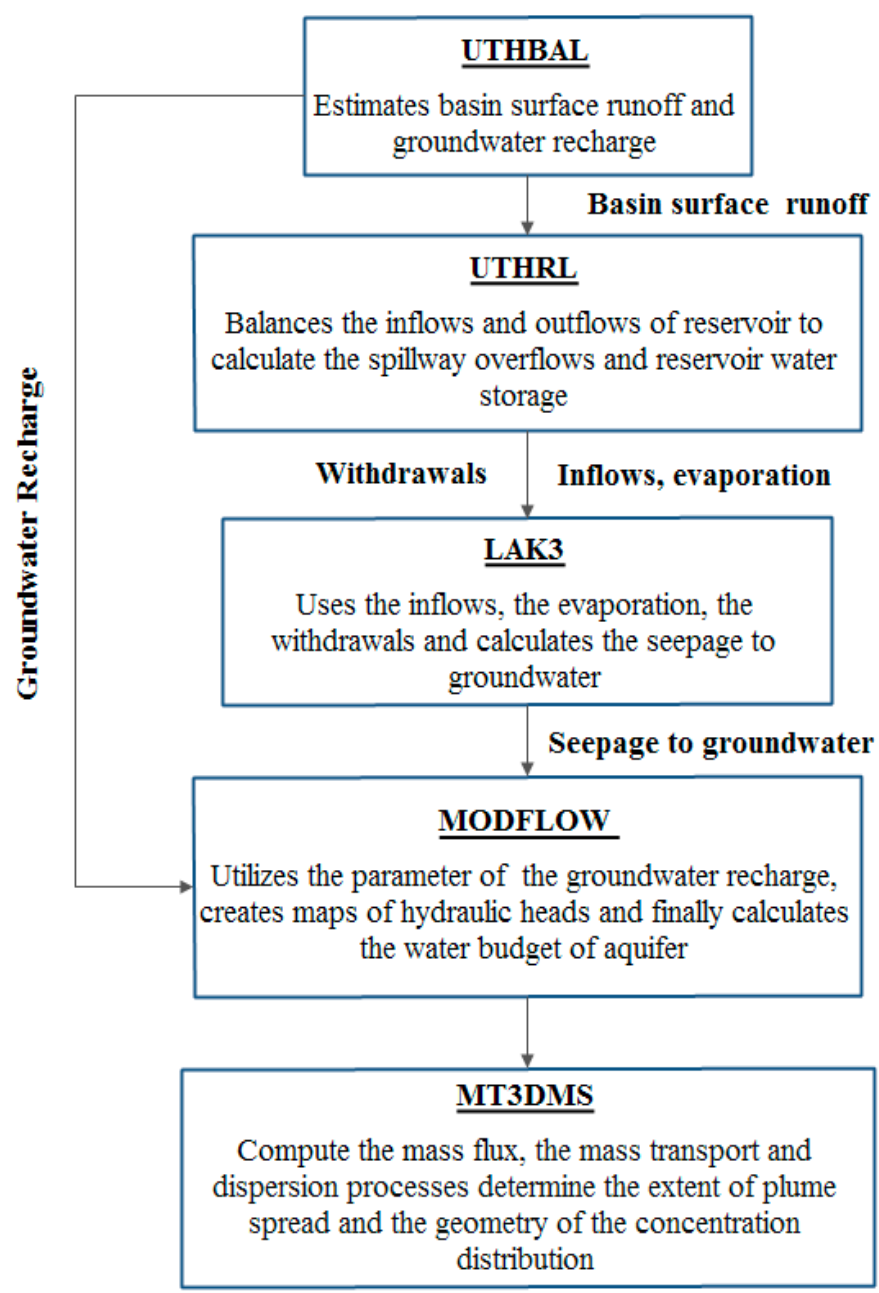

Figure 2. Integrated modeling system of the study.

In this study, the nitrate fate on groundwater is examined according to two operational scenarios. The first one examines the current situation without the reservoir operation, while the second one includes reservoir operation. Since reservoir will cover the irrigation needs of the cultivations, many irrigation wells will be closed as proposed [13]. Therefore, UTHRL and LAK3 have been applied only for the second scenario. At this point it is worth to mention that the agricultural practices and crops pattern which are applied remain stable on both scenarios. 


\section{Nitrate Transport and Dispersion Model}

The mass transport process determines the extent of the plume spread and the geometry of the distribution on groundwater contaminants concentration. The Nitrate mass transport process on the groundwater is dominated by advection-dispersion. Nitrates is dispersed longitudinally and transverse drifting by groundwater flow [14]. It is recognized that dispersivity depends on geological characteristics. Concerning the geology of Lake Karla aquifer, the longitudinal dispersivity (aL) was set to $20 \mathrm{~m}$. and the transverse dispersivity (ат) value was equal to 0.1 [15]. The parameter of molecular diffusion was considered as neglected $[6,16]$. The effective porosity used is 0.3 [9]. For nitrate transport modeling, advective flux masses are defined at flow sources/sinks [14]. Cultivation data were obtained from the Integrated Management System of cultivated areas [17]. The spatial reference of cultivations has been done with the use of a Geographical Information System at Municipal District Scale (Figure 3). The volume of nitrate leaching to the aquifer estimated by the empirical equation (Equation (1)), that is approximately $30 \%$ to $50 \%$ of the applied nitrogen fertilizer leaches to groundwater in the nitrate form [16]. Furthermore, the nitrate loading parameter based on bibliography research [18]. The MT3DMS code was used for the nitrate fate and transport simulation.

$$
\frac{\text { nitrate loading }\left(\frac{\mathrm{kg}}{\mathrm{day}}\right) * 0.4}{\frac{\text { recharge }}{365}(\mathrm{~mm}) * \text { cultivated area }\left(\mathrm{m}^{2}\right)}
$$

Transient mass transport starts from the June of 1995 and terminates by the September of 2007. In this period the systematic observation of groundwater quality was implemented by the Institute of Geological and Mineral Exploration [19]. Nitrate concentrations from 11 observation wells have been used as initial values. The locations of these observation wells are presented in Figure 3.

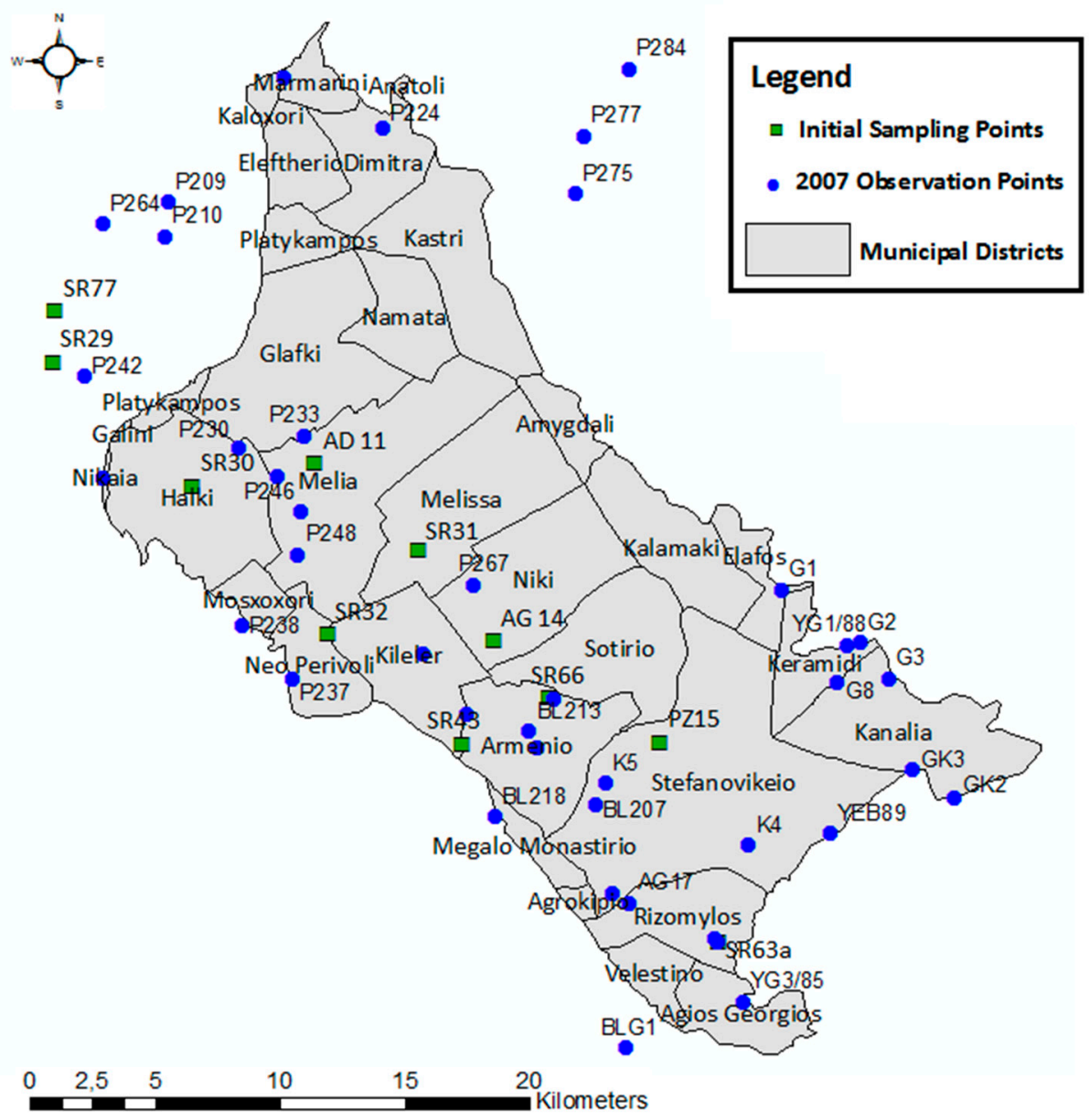

Figure 3. Location of wells and Municipal Districts. 


\section{Results}

\subsection{Surface Hydrological Model (UTHBAL)}

The UTHBAL model is applied to semi-distributed mode simulating the runoff generated from the lowland area, where the aquifer is located in and receives the percolation from that area. Since, there is no difference of climatic conditions, the results of UTHBAL are the same for the two operational scenarios. The mean annual recharge is calculated to be $15.93 \mathrm{hm}^{3}$ for the low zone and $98.43 \mathrm{hm}^{3}$ for the upper zone respectively. Furthermore, the mean annual surface runoff is estimated to be $32 \mathrm{hm}^{3}$ for the low and $60.61 \mathrm{hm}^{3}$ for the upper zone.

\subsection{Water Reservoir Model (LAK3)}

Among the results of LAK3, the only variable affecting the methodology is the groundwater seepage from the reservoir which is estimated, for the second scenario, to be $18 \mathrm{hm}^{3}$ on an annual basis [13].

\subsection{Groundwater Flow Simulation (Modflow)}

In the first scenario the over-exploitation of the aquifer is obvious, as $80 \mathrm{hm}^{3}$ of water are extracted per year from its non-renewable resources. This leads to hydraulic head drawdown to the absolute height of $-50 \mathrm{~m}$, as shown in Figure 4a. In the second scenario, only $10.84 \mathrm{hm}^{3}$ per year of groundwater non-renewable resources are exploited concluding to a very small hydraulic head drawdown not below the absolute height of $10 \mathrm{~m}$ (Figure $4 \mathrm{~b}$ ). This is due to irrigation wells closeness and to water reservoir seepage to aquifer.

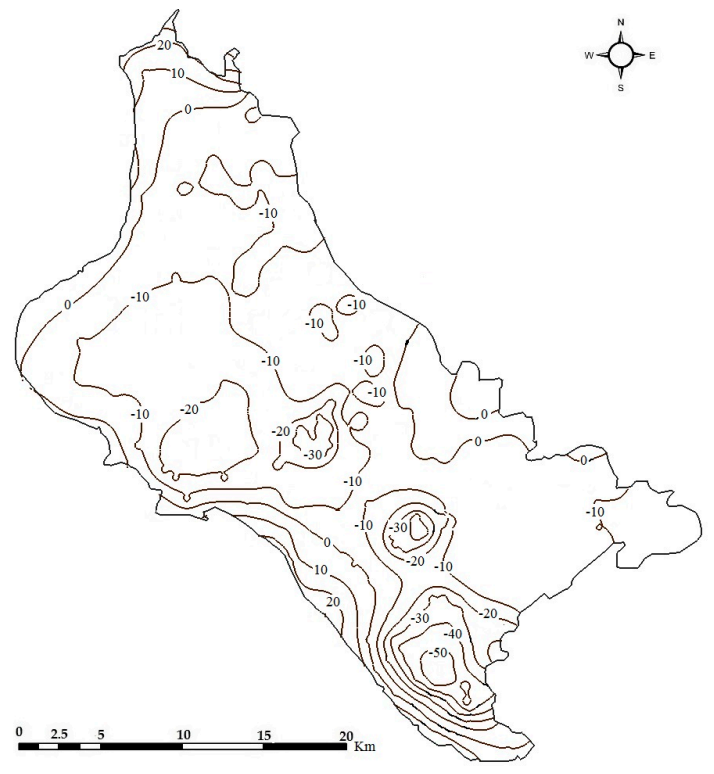

(a)

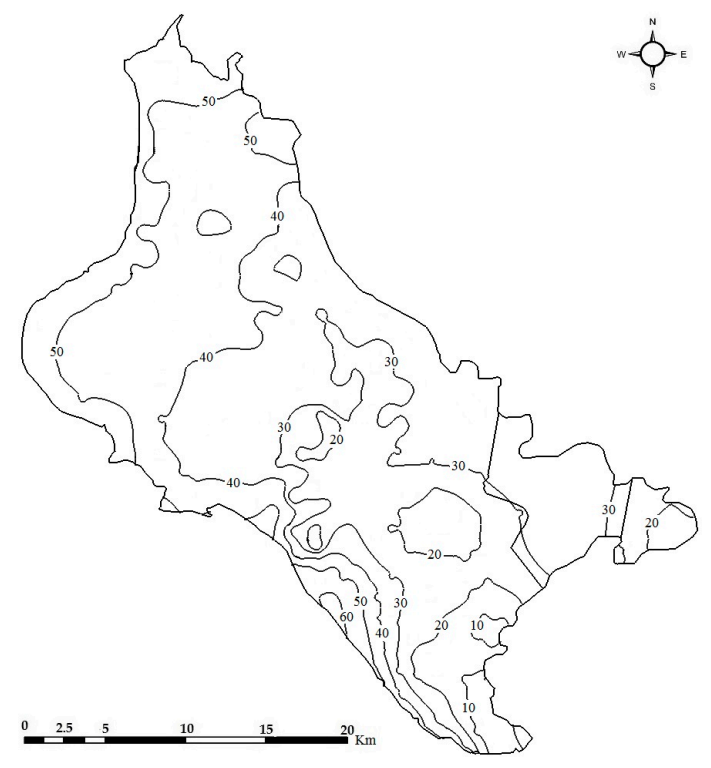

(b)

Figure 4. The hydraulics heads on the operational scenarios. (a) Presents the hydraulic heads at the first operational scenarios and (b) indicates the hydraulic heads at the second operational scenarios.

\subsection{Transport and Dispersion Model}

A sensitivity analysis has been performed to identify the most sensitive parameters affecting groundwater contamination [20]. Sensitivity analysis indicates that neither the hydraulic coefficients (hydraulic conductivity, porosity) nor the hydrodynamic dispersion coefficients of longitudinal and transverse dispersion $(\alpha \mathrm{L})$ and $(\alpha \mathrm{T})$, influence significantly the nitrate transport and dispersion. On the contrary, nitrate leaching is the parameter with the greatest uncertainty. Therefore, the model is calibrated based on the nitrate infiltration parameter (Figure 5). 
The simulation results indicate the contribution of reservoir to groundwater quality remediation. As far as the first scenario is concerned, the nitrate concentrations that are recorded are especially elevated reaching even $45 \mathrm{mg} / \mathrm{L}$, locally. The elevated nitrate concentrations are explained due to the application of nitrogen over fertilization in the region. The value of $45 \mathrm{mg} / \mathrm{L}$ is observed at south eastern part as well as the south-western part of the study area. On the contrary, with respect to the second scenario the nitrate concentration is considerably lower. The lower nitrate concentrations which are presented vary between 25 and $30 \mathrm{mg} / \mathrm{L}$. At this point, it is important to mention that the lowest value of the nitrate concentration is observed in the south eastern part of the aquifer. This is explained by the fact that this is the region where the reservoir is placed (Figure $6 a, b$ ). The presence of the reservoir signals increased recharge. Subsequently, the increased recharge leads to lower nitrate concentration (as nitrates are water soluble contaminants). Comparing the two operational scenarios, the differences of nitrate concentration values in the surrounding area of reservoir range from 10 to $15 \mathrm{mg} / \mathrm{L}$.

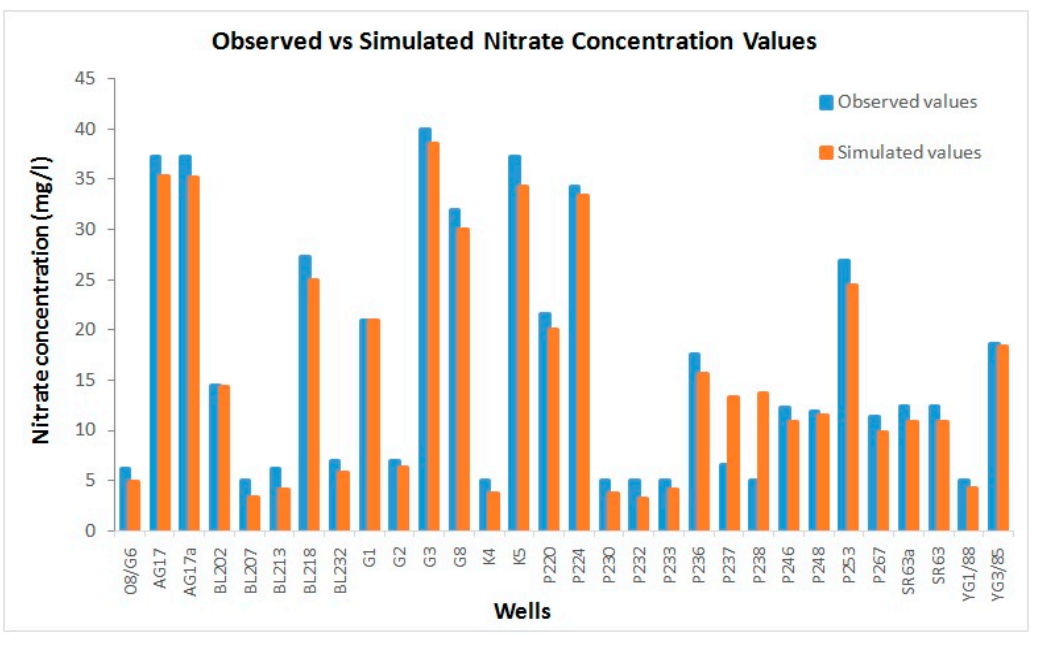

Figure 5. Comparison of the observed and simulated nitrate concentration values.

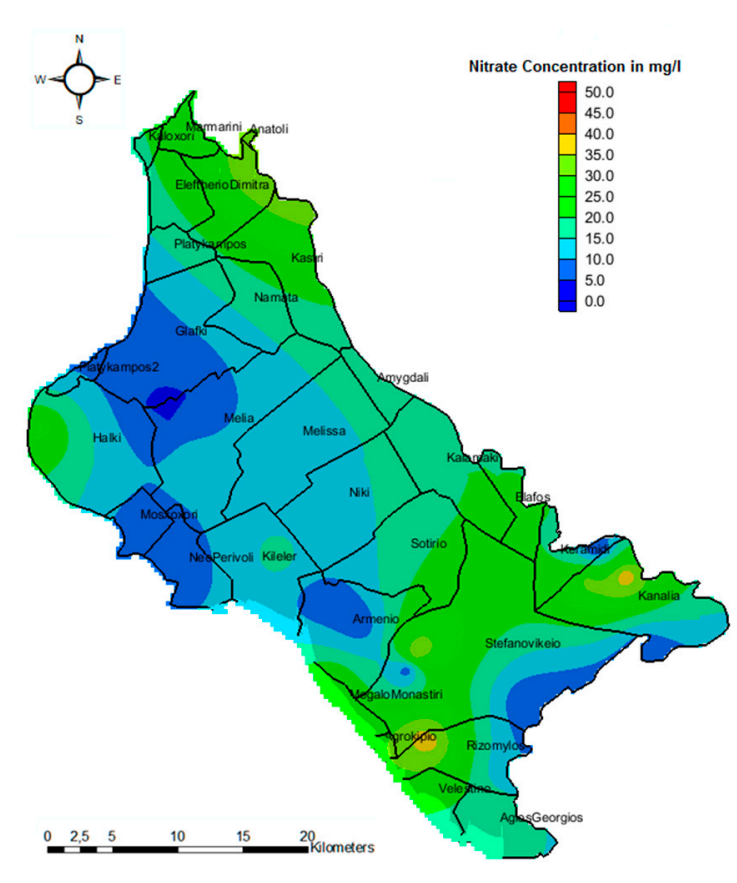

(a)

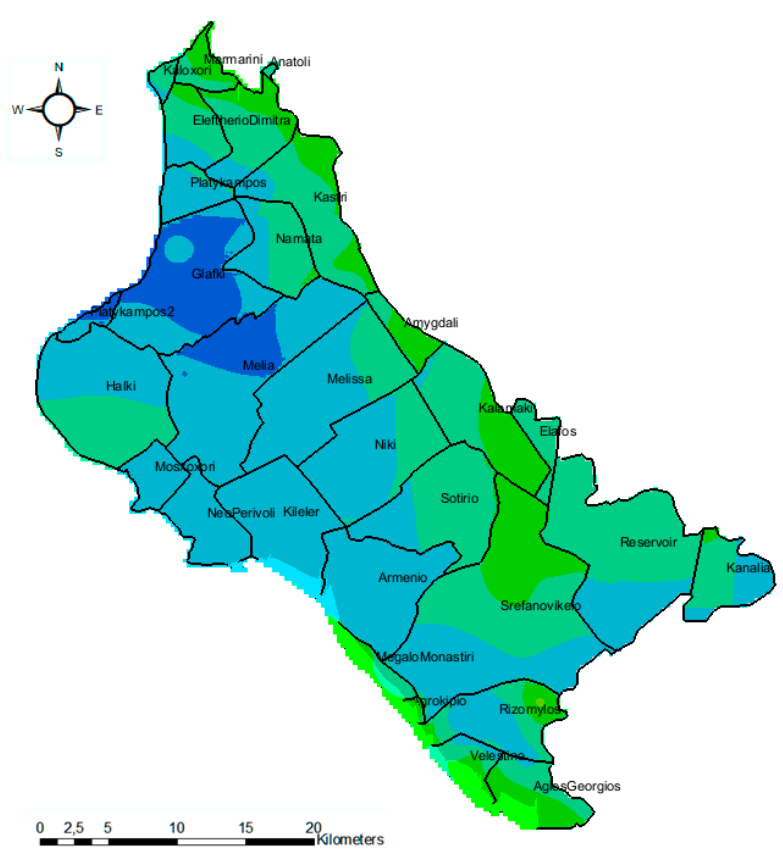

(b)

Figure 6. (a) records the nitrate concentration in the no reservoir scenario; Conversely (b) indicates the nitrate concentration in the reservoir scenario. 


\section{Conclusions}

As a conclusion it should be mentioned that the purpose of the study was to highlight the importance of a reservoir using an integrated approach on water resources management. The proposed integrated modeling focuses on the positive contribution of reservoir on groundwater quality, especially to the nitrate parameter. Nitrate transport modeling shows rising nitrate concentration on groundwater correlate with fertilizer application rates in the watershed in the case of the no reservoir scenario. Conversely, the presence of the reservoir leads to the decreasing nitrate concentration on groundwater that is explained by the reservoir's increased recharge. Therefore, as previous work was reported [21], there is a decrease in the concentration of nitrates ions in regions where there is an increased recharge. However, one important factor is the fact that the operation of the reservoir decreases locally the nitrate concentration even below the $25 \mathrm{mg} / \mathrm{L}$ in the surrounding areas. The concentration of $25 \mathrm{mg} / \mathrm{L}$ in the ground water has been characterized as a "threshold" value by Directive 91/676/EEC. The continuous existence of nitrate concentration above this "threshold" value defines the water as improper for domestic use due to the health problems it may cause. To invert this environmental degradation, radical measures ought to be taken in the study area such as the application of good agriculture practices to prevent water pollution and the adoption of efficient irrigation methods.

Author Contributions: P.S. applied and simulated the groundwater flow as well as the reservoir operation simulation. G.T. and P.S. applied and simulated the advection and dispersion of nitrates. L.V. applied and simulated the surface hydrological processes and the inflows and outflows of the reservoir. G.P. analyzed the data and created the maps utilizing Geographical Information Systems. Finally N.M. and A.L. had the supervision of all the process as well as the supervision of writing the paper.

Acknowledgments: The scientific publication was held within the framework of the invitation "Granting of scholarship for Post-Doctoral Research" of the University of Thessaly, which is being implemented by the University of Thessaly and was funded by the Stavros Niarchos Foundation. Georgios Tziatzios has been cofinanced-via a programme of State Scholarships Foundation (IKY)-by the European Union (European Social Fund-ESF) and Greek national funds through the action entitled "Scholarships programme for postgraduates studies-2nd Study Cycle" in the framework of the Operational Programme "Human Resources Development Program, Education and Lifelong Learning" of the National Strategic Reference Framework (NSRF) 2014-2020.

Conflicts of Interest: The authors declare no conflict of interest. The founding sponsors had no role in the design of the study; in the collection, analyses, or interpretation of data; in the writing of the manuscript, and in the decision to publish the results.

\section{References}

1. Crystal Ng, G.H.; Wickert, A.D.; Somers, L.D.; Saberi, L.; Cronkite-Ratcliff, C.; Niswonger, R.G.; McKenzie, J.M. GSFLOW-GRASS v1.0.0: GIS-enabled hydrologic modeling of coupled groundwater-surface-water systems. Geosci. Model. Dev. Dis. 2018, doi:10.5194/gmd-2017-321.

2. Tian, Y.; Zheng, Y.; Zheng, C. Development of a visualization tool for integrated surface watergroundwater modeling. Comput. Geosci. 2016, 86, 1-14, doi:10.1016/j.cageo.2015.09.019.

3. Zajac, Z.; Revilla-Romero, B.; Salamon, P.; Burek, P.; HirpaFeyera, A. The impact of lake and reservoir parameterization on global stream flow simulation. J. Hydrol. 2016, 548, 552-568, doi:10.1016/ j.jhydrol.2017.03.022.

4. Yihdego, Y.; Webb, J.A.; Vaheddoost, B. Highlighting the Role of Groundwater in Lake-Aquifer Interaction to Reduce Vulnerability and Enhance Resilience to Climate Change. Hydrology 2017, 4, 1-18, doi:10.3390/hydrology4010010.

5. Peña-Haro, S.; Velazquez, P.M.; Sahuquillo, A. A hydro-economic modelling framework for optimal management of groundwater nitrate pollution from agriculture. J. Hydrol. 2010, 373, 193-203, doi:10.1016/j.jhydrol.2009.04.024.

6. Almasri, M.N.; Kaluarachchi, J.J. Modeling Nitrate contamination of groundwater in agricultural watersheds. J. Hydrol. 2007, 343, 211-229, doi:10.1016/j.jhydrol.2007.06.016. 
7. Narula, K.K.; Gosain, A.K. Modeling hydrology, groundwater recharge and non-point nitrate loadings in the Himalayan Upper Yamuna basin. Sci. Total Environ. 2013, 468, 102-116, doi:10.1016/j.scitotenv.2013.01.022.

8. Loukas, A.; Mylopoulos, N.; Vasiliades, L. A modeling system for the evaluation of water resources management strategies in Thessaly, Greece. Water Resour. Manag. 2007, 21, 1673-1702, doi:10.1007/s11269006-9120-5.

9. Sidiropoulos, P.; Mylopoulos, N.; Loukas, A. Optimal management of an overexploited aquifer under climate change: The Lake Karla case. Water Resour. Manag. 2013, 27, 1635-1649, doi:10.1007/s11269-0120083-4.

10. Merritt, M.L.; Konikow, L.F. Documentation of a Computer Program to Simulate Lake-Aquifer Interaction Using the MODFLOW Ground-Water Flow Model and the MOC3D Solute-Transport Model; Water-Resources Investigations Report 00-4167; U.S. Geological Survey: Reston, VA, USA, 2000.

11. Harbaugh, A.W.; McDonald, M.G. User's Documentation for MODFLOW-2000, an Update to the U.S. Geological Survey Modular Finite-Difference Ground-Water Flow Model; United States Government Printing Office: Washington, DC, USA, 2000.

12. Zheng, C.; Wang, P.P. MT3DMS: A Modular Three-dimensional Multi-species Transport Model for Simulation of Advection, Dispersion and Chemical Reactions of Contaminants in Groundwater Systems, Documentation and User's Guide; Army Corps of Engineers: Washington, DC, USA, 1999.

13. Sidiropoulos, P.; Mylopoulos, N.; Loukas, A. Stochastic simulation and management of an over-exploited aquifer using an integrated modeling system. Water Resour. Manag. 2015, 29, 929-943, doi:10.1007/s11269014-0852-3.

14. Sharma, M.K.; Jain, C.K.; Rao, G.T.; Rao, V.V. Modelling of lindane transport in groundwater of metropolitan city Vadodara, Gujarat, India. Environ. Monit. Assess. 2015, 187, 295, doi:10.1007/s10661-0154522-6.

15. Gelhar, L.; Welty, C.; Rehfeldt, K.A. Critical review of data on field-scale dispersion in aquifers. Water Resour. Res. 1992, 28, 1955-1974, doi:10.1029/92WR00607.

16. Siarkos, I.; Kouvaritaraki, D.; Charcharidou, A.; Theodosiou, N. Modelling the Effect of Agricultural activities on Groundwater Quality in the Aquifer of N. Moudania. In Proceedings of the 13th International Conference on Environmental Science and Technology, Athens, Greece, 5-7 September 2013.

17. Ministry of Rural Development and Food. Data on the Integrated Management System of Cultivated Areas; Ministry of Rural Development and Food: Athens, Greece, 1995-2007.

18. Wichmann, W. World Fertilizer Use Manual; BASF AG: Berlin, Germany, 1992.

19. Institute of Geological and Mineral Exploration. Recording and Evaluation of the Hydrogeological Characteristics of the Groundwater Systems of the Country; Basement of the Aquatic Potential of Thessaly; Institute of Geological and Mineral Exploration: Thessaloniki, Greece, 2010.

20. Tziatzios, G.; Sidiropoulos, P.; Vasiliades, L.; Mylopoulos, N.; Loukas, A. Simulation of nitrate contamination in Lake Karla aquifer. In Proceedings of the 14th International Conference on Environmental Science and Technology CEST2015, Rhodes, Greece, 3-5 September 2015.

21. Antonakos, A.; Lambrakis, N. Hydrodynamic characteristics and nitrate propagation in Sparta aquifer. Water Resour. Res. 2000, 34, 3977-3986, doi:10.1016/s0043-1354(00)00160-3.

(C) 2018 by the authors. Licensee MDPI, Basel, Switzerland. This article is an open access article distributed under the terms and conditions of the Creative Commons Attribution (CC BY) license (http://creativecommons.org/licenses/by/4.0/). 